\title{
Use of CAE-Systems at Evaluation of Shock Absorbers for Metallurgical Equipment
}

\author{
Viktor Artiukh ${ }^{1, a}$, Talzhan Raimberdiyev ${ }^{2}$ and Vladlen Mazur ${ }^{3}$ \\ ${ }^{1}$ St. Petersburg State Polytechnical University, Polytechnicheskaya, 29, Saint-Petersburg, 195251, Russia \\ ${ }^{2}$ Hoja Akhmet Yasawi International Kazakh-Turkish University, Sattarkhanova, 29, Turkestan, 161200, Kazakhstan \\ ${ }^{3}$ LLC "Saint-Petersburg Electrotechnical Company", Pushkin, Parkovaya, 56, Saint-Petersburg, 196603, Russia
}

\begin{abstract}
Work presents results of strength calculations of absorber elastic element that were done by CAE-system and standard method of calculating. It is shown, that use of FEM software allows studying thoroughly the distribution of appropriate stresses on surfaces of elastic element.
\end{abstract}

\section{Introduction}

At current economic conditions it is necessary to design new equipment during short terms in order to increase its competitiveness. There are a lot of different features of FEM calculations done for big complex and sometimes unique details [1-5]. Mathematical model (MM) which is a basis for any technical task in CAE-system (Computer - Aided Engineering system) should be universal with possibility to change numerous parameters. The most popular MM is one which is created by means of CAD-system (Computer - Aided Design system) with FEM [6-9].

\section{Materials and Methods}

According to authors of this article, preferred CAE-system for making design and stress calculations of metallurgical equipment might be SolidWorks - COSMOSWorks. In addition, some key producers of metallurgical heavy machinery use SolidWorks - COSMOSWorks $[10,11]$. Also, it is well known about stress calculations of details from different steel grades [12-14] but there is a lack of information about use of FEM for stress calculations of absorbers elastic elements of metallurgical equipment [15-18].

Example of elastic elements FEM stress calculation is given below. It is done for elastic strip (polyurethane grade adiprene L-167), which is a part of absorber for equipment base installed on foundation. Sketch of elastic strip is shown on fig. 1.

${ }^{a}$ Corresponding author : artiukh@mail.ru

This is an Open Access article distributed under the terms of the Creative Commons Attribution License 4.0, which permits unrestricted use, distribution, and reproduction in any medium, provided the original work is properly cited. 


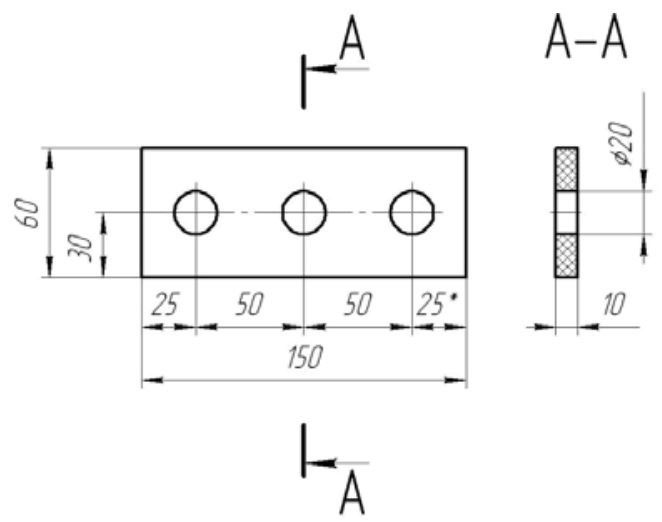

Figure 1. Sketch of the elastic strip from polyurethane grade adiprene L-167.

MM was created in SolidWorks - COSMOSWorks for making stress calculation of the elastic strip from polyurethane grade adiprene L-167. The MM strip has particular design and material properties (elastic modulus $\mathrm{E}=60 \mathrm{MPa}$, Poisson's ratio $\mu=0,495$ ). The elastic strip undergone by compressive force.

Maximum loading of the strip during usage of absorber is equal to its uniform shrink by $2 \mathrm{~mm}$. Scheme of the strip loading is shown on fig. 2.

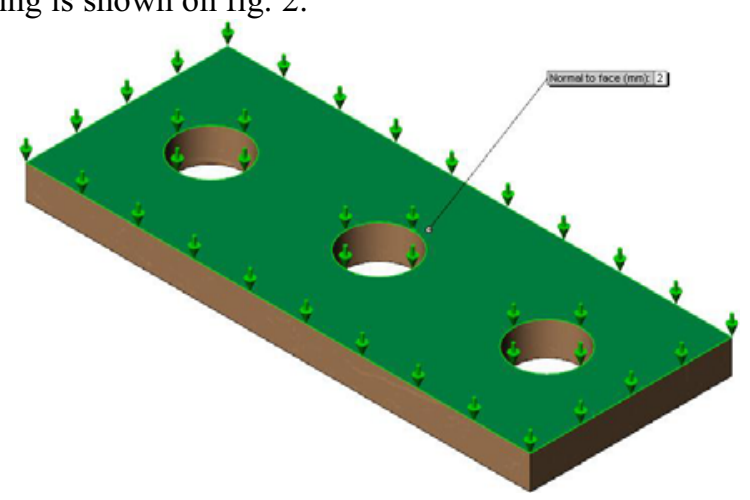

Figure 2. Scheme of the absorber strip loading by deformation in MM.

Boundary conditions were done according to recommendations [12] such as zero movement of surfaces normal to their face (refer to fig. 3).

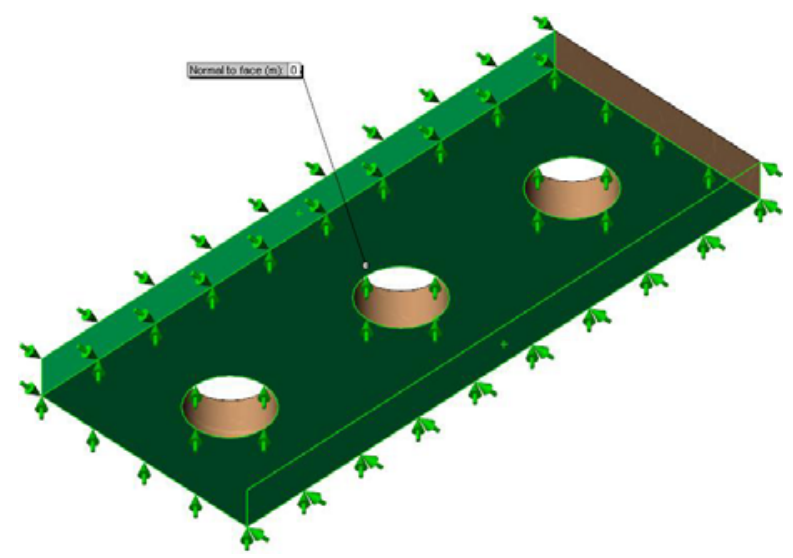

Figure 3. Loading scheme of the strip. 
Stress calculation sequence of the absorber strip was done according to recommendations [7, 11], that made it possible to clarify dimensions of elements equal to $1 \mathrm{~mm}$ with tolerance of $0.05 \mathrm{~mm}$, amount of mesh nodes is 703049; amount of mesh elements is 494837.

Calculation results of normal stress in X-axis (SX direction) are shown on fig. 4, where maximum value of normal stress $\sigma_{S X \text { max MM }}$ is in node number 693380 and $\sigma_{S X \text { MM }}^{693380}=-22,65 \mathrm{MPa}$. It means that $\sigma_{S X \text { max MM }}=\sigma_{S X \text { MM }}^{693380}$.

It is clear that nodes number 693380 and number 702954 are positioned symmetrical in reference to the central hole of the strip. Hence, accuracy of the stress calculation of MM is

$$
\Delta_{M M}=\frac{\sigma_{S X \mathrm{MM}}^{693380}-\sigma_{S X \mathrm{MM}}^{702954}}{\sigma_{S X \mathrm{MM}}^{693380}} \cdot 100,
$$

where $\sigma_{S X \text { MM }}^{702954}=-22,02 \mathrm{MPa}-$ value of normal stress in node number 702954 .

Among shown stress calculation results on fig. 4 the biggest value of normal stresses in $\mathrm{X}$-axis on lateral surface (LS) of the strip $\sigma_{S X \max M M}^{L S}$ is in node number 1451 and it is equal to $\sigma_{S X \text { MM }}^{L S 1451}=-7,797 \mathrm{MPa}$. It means that $\sigma_{S X \max \mathrm{MM}}^{L S}=\sigma_{S X \text { MM }}^{L S} 1451$

Maximum value of normal stress $\sigma_{S X \text { MM }}^{693380}$ is possible to compare with allowable stress of polyurethane [19] which can be equal to:

$$
\left[\sigma_{S X}\right] \approx 0,4 \cdot E=0,4 \cdot 60=24 \mathrm{MPa},
$$

It confirms fulfillment of strength stipulation $\left|\sigma_{S X \text { MM }}^{693380}\right|<\left[\sigma_{S X}\right],|-22,65| \mathrm{MPa}<24 \mathrm{MPa}$.

Shown stress calculation of the elastic strip can be compared to theoretical/standard calculation shown in [20]. Geometrical characteristics of the strip with three equal round holes are taken into account. Scheme that describes interconnection of FEM and theoretical calculations is shown on fig. 5, where $\sigma_{S X \text { T }}^{\mathrm{A}}$ is normal stress in point $\mathrm{A}$ acting in $\mathrm{X}$-axis on surface of the strip contour, i.e. geometrical position of node number 693380 of $\mathrm{MM}$ and point $\mathrm{A}$ of theoretical calculation are coincide. It means they have the same stress $\sigma_{S X \text { T }}^{\mathrm{A}}=\sigma_{S X \text { MM }}^{693380}=-22,65 \mathrm{MPa}$.

Deviation of results of FEM and theoretical calculations is

$$
\Delta=\frac{\sigma_{S X \quad \mathrm{MM}}^{L S}-\sigma_{S X \max \mathrm{T}}^{\mathrm{i}}}{\sigma_{S X \text { MM }}^{L S} 1451} 100,
$$

where $\sigma_{S X \max T}^{\mathrm{i}}-$ maximum value of normal stress in i-point of lateral surface acting in particular direction. 


\section{MATEC Web of Conferences}

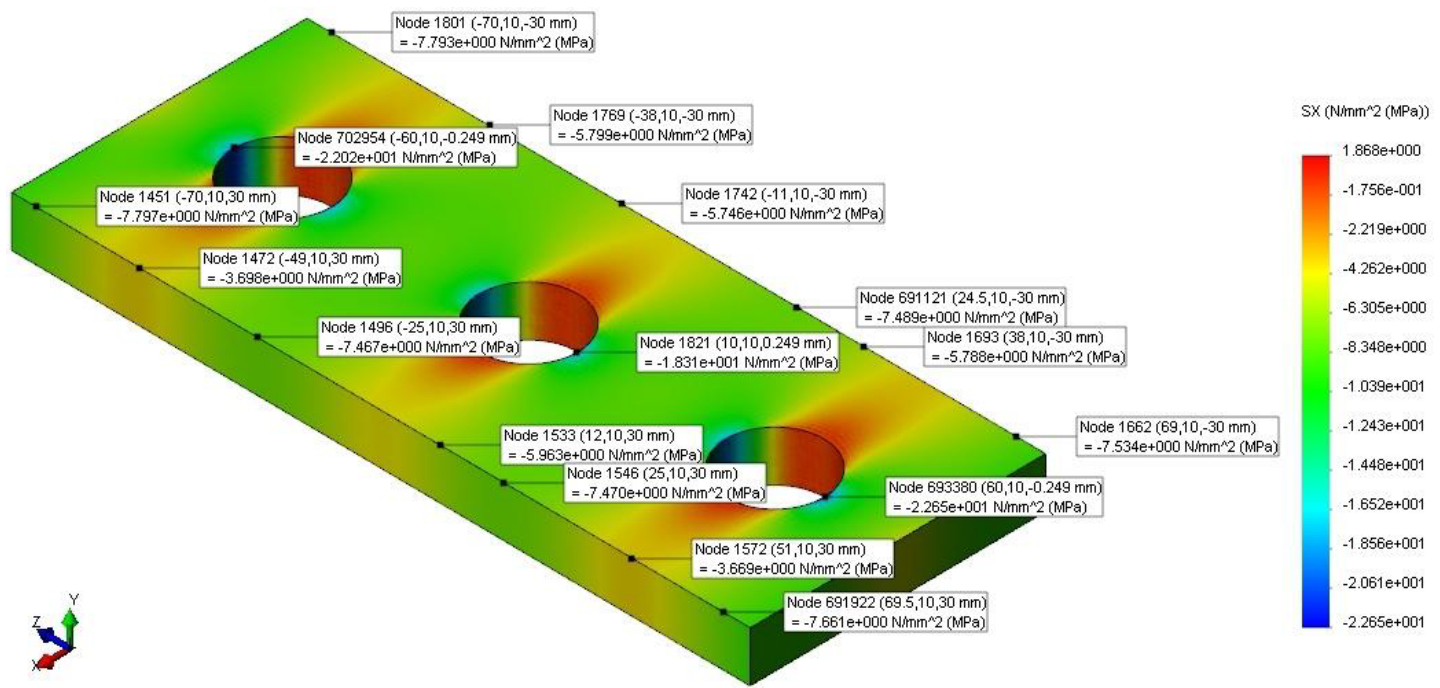

Figure 4. Distribution of normal stress acting in $\mathrm{X}$-axis in the absorber strip.

Maximum stress in i-point of lateral surface:

$$
\sigma_{S X \max \mathrm{T}}^{\mathrm{i}}=\frac{\sigma_{S X \mathrm{~T}}^{\mathrm{A}}}{K_{\mathrm{T}}^{\mathrm{A}}},
$$

where $K_{\mathrm{T}}^{\mathrm{A}}=2,975$ - coefficient when taking into account dimensions of strip and amount of uniform round holes [20].

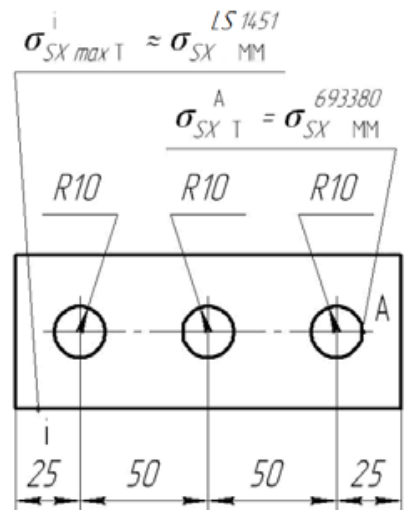

Figure 5. Interconnection scheme of FEM and theoretical calculations.

Results of FEM and theoretical stress calculations of absorber strip are given in table 1 .

Table 1. Analyses results of MM and theoretical stress calculation.

\begin{tabular}{ccc}
\hline Parameter & $\Delta_{M M}, \%$ & $\Delta, \%$ \\
\hline Value & 2,78 & 2,36 \\
\hline
\end{tabular}

\section{Conclusions}

According to described above and values in table 1 it is clear that use of CAD-systems allows to 
make relationships between parameters of elasticity theory and set of design features of developed elastic elements for absorbers of metallurgical equipment.

\section{Acknowledgments}

This article is written under grant «Verification and development of models of inelastic deformation at the passive loading» of Russian Foundation for Basic Research.

\section{References}

[1] B.N. Polyakov, Optimization and improvement of billet and sheet rolling mills (Machines builder, 11, 39-48, 2005)

[2] V.G. Artiukh, Precision of Safety Devices for Iron and Steel Machines (Mariupol: PSTU, 177, 2000)

[3] V.G. Artiukh, Loads and Overloads of Iron and Steel Machines (Mariupol: PSTU, 246, 2008)

[4] V.G. Artiukh, Basis of Protection of Metallurgical Machines from Breakdown (Mariupol: Publishing Group "University", 288, 2015)

[5] Mohammed I. Matarneh, Nabeel S. Gharaibeh, V.G. Artyukh, IJESIT, 4(2), 1-7, (2015)

[6] Y.I. Nyashin, A.N. Skorokhodov, etc, Matrix method of the solution of elastoplastic problems in the theory of metal forming (Theory of rolling, M: Metallurgy, 75-77, 1980)

[7] A.V. Chigaryov, A.S. Kravchyuk, etc, ANSYS for engineers (Mechanical engineering, 512, 2004)

[8] E.A. Nekliudova, A.S. Semenov, S.G. Semenov, B.E. Melnikov, Applied Mechanics and Materials, 725-726, 648-653, (2015)

[9] I. Maniak, B. Melnikov, A. Semenov, S. Saikin, Applied Mechanics and Materials, 725-726, 943-948, (2015)

[10] V. Sevastyanov, A. Volvach, Computer design and technical flow of documents, 2, 28-31, (2007)

[11] A.V. Belevich, A.V. Goncharuk, etc, Universities News: Nonferrous Metallurgy, 9, 32-35, (2002)

[12] A.A. Alyamovskiy, SolidWorks/COSMOSWorks. Engineering FEM analysis (DMK Press, 432, 2004)

[13] H. Magnus, Prediction of Roll Torque in Hot Rod and Wire Rolling (Örebro University, 77, 2004)

[14] A.B. Kaplun, etc, ANSYS in Engineer's Hands. Practical issue (Editorial URSS, 272, 2003)

[15] V. Mazur, V. Artyukh, G. Artyukh, M. Takadzhi, Engineering Designer, V.37, No.1, 26-29, (2012)

[16] Firas M.F. Al-Quran, M.E. Matarneh, V.G. Artukh, Research Journal of Applied Sciences, Engineering and Technology, 4(11), 1585-1589, (2012)

[17] Nabeel S. Gharaibeh, Mohammed I. Matarneh, V. G. Artyukh, Research Journal of Applied Sciences, Engineering and Technology, 8(12), 1461-1464, (2014)

[18] V.G. Artiukh, S.Yu. Karlushin, E.N. Sorochan, Procedia Engineering, 117, 938-944, (2015)

[19] G.V. Artiukh, Protection of Metallurgical Machines from Breakdowns, 2, 91-105, (1997)

[20] G.N. Savin, V.I. Tul'chiy, Handbook of stress concentration (K.: High School, 412, 1976) 